Bangladesh Rice J. 20 (1) : 45-50, 2016

\title{
Characterization and Evaluation of Aerobic Rice Genotypes under Transplanted Condition
}

\author{
S Akter ${ }^{*}$, S Pervin ${ }^{1}, \mathrm{~K}$ M Iftekharuddaula ${ }^{2}$, A Akter ${ }^{3}$ and R Yasmeen ${ }^{1}$
}

\begin{abstract}
Due to over sinking of underground water, scarcity of irrigation water is becoming a threat to the sustainability of irrigated rice production and the concept of aerobic culture appeared prominently. Aerobic rice has the ability to grow under minimum irrigation water and minimum yield reduction occurs when grown under aerobic culture with less water. This experiment aimed to evaluate two advanced aerobic rice lines under transplanted condition in net house. Two advanced lines, IR83140B-36-B-B and IR83142-B-71-B-B and two check varieties BRRI dhan28 and BRRI dhan29 were grown in three moisture regimes. The moisture regimes included a) continuous standing water (CSW) b) saturated moisture condition (SMC) and c) moisture content at field capacity (FCM). The experimental units, drum containing $110 \mathrm{~kg}$ soil, were arranged in randomized complete block design (RCBD) with five replications. Three to four seedlings of forty days were transplanted at the soil surface of each drum. Seedlings were thinned to one plant per genotypes one week after transplanting. Genotype $x$ water interaction showed significant variation in total dry matter production, panicle length, panicle exertion rate, sterility percentage and yield contributing characters. Irrespective of the genotypes, CSW conditions favored to produce maximum number of tiller and panicle. Although BRRI dhan29 gave the highest yield at both CSW and SMC, IR83142-B-71-B-B produced the highest yield at FCM. However, BRRI dhan28 gave similar yield to that of IR83142-B-71-B-B in FCM treated drums.
\end{abstract}

Key words: Aerobic rice, moisture regimes, transplanted condition, growth characters, yield contributing characters, yield

\section{INTRODUCTION}

Irrigated rice fields of Asian countries consume more than $40 \%$ of the world's freshwater that is used for agriculture (Bouman 2001). Tuong and Bouman (2003) estimated that by 2025, approximately two million hectares of irrigated dry-season rice and 13 million hectares of wet-season rice land will experience water scarcity. The declining availability of irrigation water and increasing costs of water threaten the traditional method of cultivating irrigated rice. Moreover, due to climate change insufficient rainfall would be a major production constraint in rain-fed areas where many marginal farmers live. As water is the most limited and essential natural resource in agriculture, the dwindling water resources reveal a grim situation for lowland puddled rice cultivation. Because of increasing water scarcity, there is a need to develop alternative systems that require less water (Bouman et al., 2002).

Aerobic rice production is a revolutionary way of growing rice in non-puddled, nonflooded fields (Singh et al., 2008; Rajakumar et al., 2009) and rice is grown like an upland crop (unsaturated condition) with adequate inputs and supplementary irrigation when rainfall is insufficient (Bouman, 2001). This system uses input-responsive specialized rice cultivars and complementary management practices to achieve at least 4-6 $\mathrm{t} \mathrm{ha}^{-1}$ using only $50-70 \%$ of the water required for irrigated rice production. Varieties suitable for this type of cultivation also possess ability to withstand intermittent drought spells with minimum yield loss with maximum yield

Plant Physiology Division, ${ }^{2}$ Plant Breeding Division, ${ }^{3}$ Hybrid Rice Division, Bangladesh Rice Research Institute, Gazipur, Bangladesh. *Corresponding author's E-mail: salmabrri@gmail.com 
potential of 6 tons per hectare. Aerobic rice could be cultivated with 600 to $700 \mathrm{~mm}$ of total water in summer and entirely on rainfall in wet season (Hittalmani, 2007). So aerobic rice recommended in areas where water is too scarce or expensive to allow traditional irrigated rice cultivation. Growing rice aerobically saves water by eliminating continuous seepage and percolation, reducing evaporation and eliminating wetland preparation. It is also reported that amount of methane emitted under aerobic situation is very low and contributes to lowering of greenhouse gas emission (Hittalmani, 2007).

Suitable rice genotypes for aerobic cultivation are limited. Recently International Rice Research Institutes developed fixed lines (IR83140-B-36-B-B and IR83142-B-71-B-B), which would be suitable to grow in aerobic soil condition. These lines have not been tested for its suitability in the climatic conditions of Bangladesh. Field testing of the aerobic rice lines encounters difficulties in moisture control. Therefore, their potentiality needs to be tested under control net house conditions with different moisture regimes. Physiological characteristics (eg. photosynthesis rate and dry matter production) along with yield and yield contributing characters of the aerobic lines need to be compared with regular varieties. Therefore, a net house experiment was conducted to compare physiological traits and yield of IR83140-B-36-B-B and IR83142-B-71B-B against the Boro varieties under different moisture regimes.

\section{MATERIALS AND METHODS}

Two advanced lines IR83140-B-36-B-B and IR83142-B-71-B-B along with standard Boro varieties BRRI dhan 28 and BRRI dhan 29 were evaluated in drum $(56 \mathrm{~cm} \times 43 \mathrm{~cm})$ containing $110 \mathrm{~kg}$ soil. The soil was fertilized with UreaTSP-MP @ 50-25-25 g/drum. Forty day aged seedlings were transplanted at 21 January, 2015. Three to four seedlings were transplanted at the soil surface of each drum. Seedlings were thinned to one plant per genotypes one week after transplanting. The experiment was conducted under three water regimes as continuous standing water (CSW), saturated moisture condition (SMC) and moisture content at field capacity (FCM).Water treatment was started at tillering stage. Saturation and moisture content at field capacity were determined through the Gravimetric Method and the desired moisture contents were maintained by quantitatively adding water to the respective drums at two to three days interval. To avoid rainfall all the drums were shaded by polythene sheet. The drums were arranged in RCB design and replicated five times. Photosynthesis data was taken at maximum flowering stage considering flag leaf at the middle portion using LI-6400 portable photosynthesis system. Panicle exertion rate was measured following the formula (Length of the exerted panicle /Total length of panicle)*100. Data on other growth characters, yield and yield contributing characters were collected and analyzed by using CROPSTAT 7.2 statistical software of IRRI.

\section{RESULTS AND DISCUSSION}

\section{Growth characters}

Genotype $\times$ water regime demonstrated insignificant interaction in case of plant height, tiller number, rate of photosynthesis and days to heading (Table 1). The tested genotypes had significant variation in plant height. BRRI dhan28 produced the highest plant height followed by BRRI dhan29 and 
Table 1. Plant height, tiller number, photosynthesis rate, days to heading and total dry matter of tested genotypes at different moisture levels.

\begin{tabular}{|c|c|c|c|c|c|c|}
\hline Genotype & Treatment & $\begin{array}{c}\text { Plant } \\
\text { height }(\mathrm{cm})\end{array}$ & Tiller no. hill-1 & $\begin{array}{l}\text { Photosynthesis } \\
\left(\mu \mathrm{molCO}_{2} \mathrm{~m}^{-2} \mathrm{~s}^{-1}\right)\end{array}$ & $\begin{array}{l}\text { Day to } \\
\text { heading }\end{array}$ & $\begin{array}{l}\text { Total dry matter } \\
\left(\mathrm{g} \text { hill }^{-1}\right)\end{array}$ \\
\hline \multirow[t]{3}{*}{ IR83140-B-36-B-B } & Control & 93.2 & 22.2 & 22.0 & 115 & 54.2 \\
\hline & Saturation & 84.3 & 15.4 & 19.6 & 114 & 40.1 \\
\hline & Field capacity & 79.5 & 16.0 & 18.0 & 117 & 32.9 \\
\hline \multirow[t]{3}{*}{ IR83142-B-71-B-B } & Control & 94.6 & 20.2 & 22.6 & 111 & 75.4 \\
\hline & Saturation & 94.0 & 18.8 & 20.3 & 114 & 64.8 \\
\hline & Field capacity & 93.0 & 16.2 & 20.5 & 113 & 50.8 \\
\hline \multirow[t]{3}{*}{ BRRI dhan28 } & Control & 110.0 & 20.8 & 20.3 & 107 & 74.2 \\
\hline & Saturation & 102.2 & 15.0 & 20.5 & 108 & 54.8 \\
\hline & Field capacity & 108.4 & 15.6 & 21.4 & 110 & 44.6 \\
\hline \multirow[t]{3}{*}{ BRRI dhan29 } & Control & 107.4 & 20.8 & 18.3 & 125 & 98.5 \\
\hline & Saturation & 99.0 & 19.0 & 18.1 & 127 & 83.3 \\
\hline & Field capacity & 92.2 & 18.4 & 14.3 & 127 & 34.1 \\
\hline $\begin{array}{l}\text { LSD } 0.05 \text { for genotype } \\
\text { (G) }\end{array}$ & - & 5.4 & $2.6^{\mathrm{ns}}$ & 3.2 & 1.7 & 10.8 \\
\hline $\begin{array}{l}\text { LSD }_{0.05} \text { for moisture } \\
\text { level (M) }\end{array}$ & - & 4.7 & 2.2 & 2.8 & 1.5 & 9.4 \\
\hline $\operatorname{LSD}_{0.05}$ for $\mathrm{G} \times \mathrm{M}$ & - & $9.4^{\mathrm{ns}}$ & $4.5 \mathrm{~ns}$ & $5.6 \mathrm{~ns}$ & $3.0 \mathrm{~ns}$ & 18.8 \\
\hline
\end{tabular}

the advanced lines (IR83140-B-36-B-B and IR83142-B-71-B-B) had relatively shorter plants height. This is due to the varietal differences of the tested genotypes. Water treatment produced significant effect on the plant height and tiller number per plant as well. Irrespective of genotypes, maximum plant height and tiller number per plant was observed in continuous standing water condition and minimum in field capacity condition (Table 1). Bakul et al. (2009) observed reduced tiller production under moisture stress condition.

Rate of photosynthesis at flowering stage also showed insignificant interaction. But effect of genotypes and water regimes was significant for this trait. Assimilation rate was statistically similar for the genotype IR83142B-71-B-B, BRRI dhan28 and BRRI dhan29 at CSW and SMC condition. But moisture content at field capacity BRRI dhan29 had the lowest assimilation rate whereas BRRI dhan 28 and IR83142-B-71-B-B showed the highest assimilation (Table. 1). Patel et al. (2010) reported similar results where genotypes having high photosynthesis rate performed better at water deficit condition.
Genotype $x$ water regime showed significant interaction for total dry matter production (Table 1). Maximum total dry matter was produced in BRRI dhan29 followed by IR83142-B-71-B-B at CSW condition and SMC condition. But moisture content at field capacity IR83142-B-71-B-B and BRRI dhan 28 produced maximum amount of total dry matter. Genotype IR83140-B-36-B-B produced minimum amount of total dry matter at all moisture regimes (Table 1). These findings are in accordance with the results obtained by Patel et al. (2010) where dry matter accumulation is more in CSW condition than moisture content at field capacity. Because water deficit at the vegetative stage hampered crop growth and development and reduced the number of tillers and dry matter. Significant variation was not observed for heading date at different moisture regimes. Days to heading was recorded minimum in BRRI dhan28 and maximum in BRRI dhan29 than other two genotypes (Table 1). Variation in what are the growth characters as total dry matter and photosynthesis rate among the genotypes under aerobic condition are useful to determine the appropriate aerobic rice 
genotypes. In this regards, IR83142-B-36-B-B was found as the best genotype under water stress condition.

\section{Yield contributing characters}

Genotype $\times$ water regime interaction showed insignificant variation for number of panicle per hill. Irrespective of genotypes, panicle number varied significantly with moisture regimes. Maximum number of panicle was observed at CSW condition and minimum at field capacity condition (Table 2). Number of panicle in genotype IR83142-B-71-B-B and BRRI dhan29 was similar at saturated moisture condition. But at field capacity condition BRRI dhan 28 produced maximum number of panicle and BRRI dhan29 produced the least number of panicle. Panicle length showed significant variation for the interaction of genotypes and water regime. Maximum panicle length was observed at continuous standing water and saturated moisture condition. Moisture content at field capacity BRRI dhan28 and BRRI dhan29 produced the highest and lowest length of panicle, respectively. Bakul et al. (2009) also observed poor emergence of panicle and reduced length of panicle under moisture stress condition.
Panicle exertion rate showed significant variation for genotype $\times$ water regime interaction (Table 2). The highest rate of panicle exertion was recorded with BRRI dhan28 at continuous standing water whereas other genotypes were statistically similar for panicle exertion. At saturated moisture condition panicle exertion rate was the highest in IR83140-B-71-B-B followed by BRRI dhan28. Moisture content at field capacity BRRI dhan29 had the least panicle exertion rate. Higher panicle exertion rate might be due to the genetic potentiality of the genotypes. However, panicle exertion rate was about 80 to $90 \%, 78$ to $91 \%$ and 64 to $89 \%$ at CSW, SMC and FCM condition, respectively. Genotype $\times$ water regime interaction showed significant variation for spikelet sterility percentage. The highest spikelet sterility percentage was observed at moisture content of field capacity for the genotype BRRI dhan29 (Table 2). High spikelet sterility was due to the water deficiency at field capacity condition. Because water stress reduced the number of tiller as well as reduced total dry matter production which ultimately increased the spikelet sterility percentage at this condition than continuous standing water condition. Begum (1990) reported that water deficit increased the number of empty spikelet per panicle.

Table 2. Panicle number, panicle length, panicle exertion rate and sterility percentage of tested genotypes at different moisture levels.

\begin{tabular}{|c|c|c|c|c|c|}
\hline Genotype & Treatment & $\begin{array}{c}\text { Panicle no. } \\
\text { hill- }^{-1}\end{array}$ & $\begin{array}{l}\text { Panicle length } \\
(\mathrm{cm})\end{array}$ & $\begin{array}{c}\text { Panicle exertion } \\
\text { rate }(\%)\end{array}$ & $\begin{array}{c}\text { Sterility } \\
\text { percentage }\end{array}$ \\
\hline \multirow[t]{3}{*}{ IR83140-B-36-B-B } & Control & 20.8 & 20.6 & 84.3 & 47.8 \\
\hline & Saturation & 13.6 & 20.8 & 90.9 & 39.2 \\
\hline & Field capacity & 13.6 & 18.3 & 86.9 & 48.9 \\
\hline \multirow[t]{3}{*}{ IR83142-B-71-B-B } & Control & 18.2 & 20.5 & 84.7 & 42.7 \\
\hline & Saturation & 16.0 & 19.6 & 80.9 & 47.7 \\
\hline & Field capacity & 13.0 & 19.0 & 80.1 & 53.2 \\
\hline \multirow[t]{3}{*}{ BRRI dhan28 } & Control & 19.0 & 21.6 & 90.4 & 36.4 \\
\hline & Saturation & 14.4 & 20.8 & 91.6 & 28.8 \\
\hline & Field capacity & 14.0 & 21.0 & 89.8 & 49.2 \\
\hline \multirow[t]{3}{*}{ BRRI dhan29 } & Control & 18.6 & 18.9 & 80.5 & 26.6 \\
\hline & Saturation & 18.2 & 19.4 & 78.9 & 27.3 \\
\hline & Field capacity & 11.8 & 14.3 & 64.0 & 70.8 \\
\hline LSD $_{0.05}$ for genotype $(G)$ & - & $2.03^{\text {ns }}$ & 1.2 & 4.5 & $9.6^{\mathrm{ns}}$ \\
\hline LSD $_{0.05}$ for moisture level (M) & - & 1.7 & 1.1 & 3.9 & 8.3 \\
\hline $\mathrm{LSD}_{0.05}$ for $\mathrm{G} \times \mathrm{M}$ & - & $3.5^{\text {ns }}$ & 2.2 & 7.8 & 16.7 \\
\hline
\end{tabular}




\section{Yield and yield component}

Number of filled grain per panicle showed significant variation for genotype $\times$ moisture regime interaction. BRRI dhan 28 and BRRI dhan 29 produced maximum number of filled grain per panicle both at CSW and SMC condition than other two genotypes (Table 3). Bakul et al. (2009) also found the similar result that water deficit reduced the number of filled grain per panicle. However, maximum number of filled grain was observed in BRRI dhan28 followed by IR83142-B-71-B-B at field capacity of soil. This is due to the production of higher total dry matter production at field capacity condition. As total dry matter has positive relation with number of filled grains per panicle. There was significant difference in 1000 grain weight among the tested genotypes. Higher grain weight was observed for the genotype IR83142-B-71-B-B at all moisture regimes than other genotypes. This is due to the varietal effect of this genotype. Grain weight (1000 grain) also varied significantly with the different water regime. However, the highest reduction for thousand grain weight was obtained at field capacity condition for all the genotypes (Table 3). This result was also in agreed with Bakul et al. (2009).
Grain yield varied significantly for the genotype $\times$ moisture regime interaction. Under CSW maximum and minimum grain yield was observed in BRRI dhan29 and IR83140-B-36-B-B, respectively. At saturated moisture condition grain yield of all tested genotypes were statistically similar with continuous standing water except BRRI dhan28. The highest grain yield was obtained with IR83142-B-71-B-B and BRRI dhan28 whereas IR83140-B-36-B-B and BRRI dhan29 gave the lowest yield at the field capacity condition (Table 3). The findings are in accordance with of Patel et al. (2010). They stated that the grain yield of rice under aerobic condition was lower than flooded condition. Decrease in grain yield of aerobic rice compared to flooded rice was also reported by Bouman et al. (2005) and Peng et al. (2006). Maximum grain yield reduction was observed in BRRI dhan28 followed by IR83140-B-36-B-B at saturated condition. There was the lowest grain yield reduction $(>50 \%)$ in IR83142-B-71-B-B both at saturated moisture and moisture content at field capacity (Table 3). The higher grain yield was obtained due to higher number of filled grain number per panicle as well as higher thousand grain weight.

Table 3. Yield and yield components of tested genotypes at different moisture levels.

\begin{tabular}{|c|c|c|c|c|c|}
\hline Genotype & Treatment & $\begin{array}{l}\text { Filled grain } \\
\text { no. panicle }{ }^{-1}\end{array}$ & $\begin{array}{c}\text { 1000-grain } \\
\text { wt (g) }\end{array}$ & $\begin{array}{c}\text { Grain yield } \\
\left(\mathrm{g} \text { hill }{ }^{-1}\right)\end{array}$ & $\begin{array}{l}\% \text { yield } \\
\text { reduction }\end{array}$ \\
\hline \multirow[t]{3}{*}{ IR83140-B-36-B-B } & Control & 56 & 20.9 & 24.5 & - \\
\hline & Saturation & 68 & 20.3 & 17.3 & 29.4 \\
\hline & Field capacity & 38 & 20.1 & 10.8 & 55.6 \\
\hline \multirow[t]{3}{*}{ IR83142-B-71-B-B } & Control & 75 & 23.5 & 32.5 & - \\
\hline & Saturation & 79 & 23.0 & 28.8 & 11.2 \\
\hline & Field capacity & 69 & 22.0 & 19.9 & 38.8 \\
\hline \multirow[t]{3}{*}{ BRRI dhan28 } & Control & 100 & 19.3 & 36.7 & - \\
\hline & Saturation & 97 & 18.1 & 25.4 & 30.6 \\
\hline & Field capacity & 72 & 18.8 & 18.2 & 50.2 \\
\hline \multirow[t]{3}{*}{ BRRI dhan29 } & Control & 132 & 18.5 & 46.7 & - \\
\hline & Saturation & 126 & 18.7 & 43.0 & 7.7 \\
\hline & Field capacity & 50 & 16.5 & 10.8 & 76.7 \\
\hline LSD $_{0.05}$ for genotype $(G)$ & - & 16 & 1.1 & 5.4 & - \\
\hline LSD $_{0.05}$ for moisture level (M) & - & 14 & 0.9 & 4.7 & - \\
\hline $\mathrm{LSD}_{0.05}$ for $\mathrm{G} \times \mathrm{M}$ & - & 28 & $1.9^{\text {ns }}$ & 9.4 & - \\
\hline
\end{tabular}




\section{CONCLUSION}

The new aerobic rice line IR83142-B-71-B-B demonstrated the least reduction in total dry matter production and grain yield among the tested genotypes under field capacity conditions. The aerobic rice line IR83142-B-71B-B may be recommended for field evaluation under water stress condition.

\section{REFERENCES}

Bakul, M R A, M S Akter, M N Islam, M M A A Chowdhury and M H A Amin. 2009. Water stress effect on morphological characters and yield attributes in some mutants T. Aman rice lines. Bangladesh Res. Pub. J. 3(2): 934-944.

Bouman, B A M, S Peng, A R Castaneda and R M Visperas. 2005. Yield and water use of irrigated tropical aerobic rice systems. Agricultural Water Management. 74:87-105.

Bouman, B A M., Wang Hua Qi, Yang Xiao Guang, Zhao Jun Fang and Wang Chang Gui. 2002. Proc. 12th International Soil Conservation Organization Conference. May, 26-31. Tsinghua University, Beijing, China.

Bouman, B A M. 2001. Water-efficient management strategies in rice production. Int Rice Res. Notes. 16:17-22.

BRRI (Bangladesh Rice Research Institute). 2013. Annual Report for 2013-14. Bangladesh Rice Research Institute, Joydebpur, Gazipur. P. 103-104.

Blackwell, J, W S Meyer and R G Smith. 1985. Growth and yield of rice under sprinkler irrigation on a freedraining soil. Australian J. of Agri. Res. 25: 636641.
Begum, F A. 1990. Effect of different levels of light and drought stress on individual spikelet filling in rice. Ph.D. Thesis, Univ. Philippines. Los Banos, College Laguna, Philippines.

Hittalmani, S. 2007. A new aerobic rice variety for water scarce situation, MAS946-1.

Aerobic rice cultivation Brochure, MAS lab, Univ. Agric. Sci., GKVK, Bangalore.

Patel, D P, Anup Das, G C Munda, P K Ghosh, J S Bordoloi, M Kumar. 2010. Evaluation of yield and physiological attributes of high-yielding rice varieties under aerobic and flood-irrigated management practices in mid-hills ecosystem. Agric. Water Manage. doi:10.1016/j.agwat.

Peng, S, B A M Bouman, M Visperas, A R Castan eda, L Nie and H K Park. 2006. Comparison between aerobic and flooded rice in the tropics: Agronomic performance in an eight-season experiment. Field Crops Res. 96: 252-259.

Rajakumar, D, E Subramanian, $\mathrm{T}$ Ramesh, N Maragatham, G J Martin and G Thiyagarajan. 2009. Striding towards aerobic rice cultivation - a review. Agricultural Reviews. 30 (3): 213- 218.

Singh, S, J K Ladha, R K Gupta, L Bhusan and A N Rao. 2008. Weed management in aerobic rice systems under varying establishment methods. Crop Protection. 27 (3-5): 660-671.

Subramanian, E and G J Martin. 2006. Effect of chemical, cultural and mechanical methods of weed control on wet seeded rice. Indian J. of Weed Sciences. 8 (3\&4): 218-220.

Tuong, T P and B A M Bouman. 2003. Rice production in water-scarce environments, In: Proc. Water Productivity Workshop, 12-14 November 2001, Colombo, Sri Lanka. International Water Management Institute, Colombo, Sri Lanka. 